\title{
Modelling spatial distribution of snails transmitting parasitic worms with importance to human and animal health and analysis of distributional changes in relation to climate
}

\author{
Ulrik B. Pedersen ${ }^{1}$, Nicholas Midzi², Takafira Mduluza ${ }^{2}$, White Soko ${ }^{3}$, Anna-Sofie \\ Stensgaard ${ }^{1,4}$, Birgitte J. Vennervald ${ }^{1}$, Samson Mukaratirwa ${ }^{5}$, Thomas K. Kristensen ${ }^{1,5}$ \\ ${ }^{1}$ Department of Disease Biology, Faculty of Health Sciences, University of Copenhagen, Fredriksberg, Denmark; \\ ${ }^{2}$ Department of Biochemestry, University of Zimbabwe, Harare, Zimbabwe; ${ }^{3}$ National Institute of Health \\ Research, Ministry of Health and Child Welfare, Harare, Zimbabwe; ${ }^{4}$ Centre for Macroecology, Evolution and \\ Climate, Natural History Museum of Denmark, University of Copenhagen, Copenhagen, Denmark; ${ }^{5}$ School of \\ Life Sciences, University of KwaZulu-Natal, Durban, South Africa
}

\begin{abstract}
The environment, the on-going global climate change and the ecology of animal species determine the localisation of habitats and the geographical distribution of the various species in nature. The aim of this study was to explore the effects of such changes on snail species not only of interest to naturalists but also of importance to human and animal health. The spatial distribution of freshwater snail intermediate hosts involved in the transmission of schistosomiasis, fascioliasis and paramphistomiasis (i.e. Bulinus globosus, Biomphalaria pfeifferi and Lymnaea natalensis) were modelled by the use of a maximum entropy algorithm (Maxent). Two snail observation datasets from Zimbabwe, from 1988 and 2012, were compared in terms of geospatial distribution and potential distributional change over this 24-year period investigated. Climate data, from the two years were identified and used in a species distribution modelling framework to produce maps of predicted suitable snail habitats. Having both climate- and snail observation data spaced 24 years in time represent a unique opportunity to evaluate biological response of snails to changes in climate variables. The study shows that snail habitat suitability is highly variable in Zimbabwe with foci mainly in the central Highveld but also in areas to the South and West. It is further demonstrated that the spatial distribution of suitable habitats changes with variation in the climatic conditions, and that this parallels that of the predicted climate change.
\end{abstract}

Keywords: vector-borne disease modelling, climate change, species distribution modelling, schistosomiasis, fascioliasis, Zimbabwe.

\section{Introduction}

Schistosomiasis and fascioliasis, two diseases caused by trematode worms, are of great concern both worldwide and in Zimbabwe. About 207 million people, $93 \%$ of whom live in sub-Saharan countries, are estimated to be infected with schistosomes among a total 779 million people at risk (Steinmann et al., 2006, Fürst et al., 2012). In Zimbabwe, the overall prevalence of schistosomiasis among school children is close to $23 \%$, and infected cases are widely distributed across the country (Midzi et al., 2011). Estimates of worldwide human fascioliasis are not well document-

Corresponding author:

Ulrik B. Pedersen

Department of Disease Biology

Faculty of Health Sciences, University of Copenhagen

Dyrlægevej 100, 1870 Frederiksberg C, Denmark

Tel. +45 3122-3866; Fax +45 3533-2755

E-mail: ubop@sund.ku.dk; ubpedersen@hotmail.com ed and range from 2.5 to 17 million (Hopkins, 1992; Rim et al., 1994; Mas-Coma, 2004; Keiser and Utzinger, 2005; Fürst et al., 2012). As in most other parts of the world, the prevalence of fascioliasis has not been intensively investigated in Zimbabwe though prevalence of up to $5 \%$ has been reported (Goldsmid, 1968; Hammond, 1974). Fascioliasis affects grazers, including domestic cattle, and in Zimbabwe we find reports of prevalence of up to $90 \%$ in some areas (Pfukenyi et al., 2005).

For the planning of successful interventions against these diseases and to target populations living in highrisk areas, it is of great importance to be able to determine the current spatial distribution of infection at a reasonably fine scale, including the distribution of parasites and host species. Nationwide prevalence-screening strategies, snail host collection field surveys, and environmental parasite sampling are rarely affordable and as a result of this, geographical modelling becomes attractive as a convenient and economical alternative. 
Many authors have reported local presence and spatial distribution of snails transmitting schistosomiasis in Zimbabwe (Shiff et al., 1979; Woolhouse and Chandiwana, 1990a; Mukaratirwa et al., 1996; Pfukenyi et al., 2006; Chimbari et al., 2007) and also of those transmitting fascioliasis (Pfukenyi et al., 2006) but none has made a complete assessment of snail distribution similar to that of Makura and Kristensen (1991), with snail data collected in 1988.

The 1988 dataset has been made available for this study and is compared to a new dataset collected in 2012. Having both climate- and snail observation data spaced 24 years apart represents a unique opportunity to evaluate the biological responses of snails to climate change. However, the objective was not only to investigate changes in snail distribution in Zimbabwe over time, but also to predict the nationwide spatial distribution of the intermediate hosts/vectors Bulinus globosus (Morelet, 1866), Biomphalaria pfeifferi (Kraus, 1848) and Lymnaea natalensis (Kraus, 1948) that support the transmission of human schistosomiasis, human fascioliasis and animal fascioliasis (Table 1).

\section{Material and methods}

\section{Study area}

Field work was conducted in Zimbabwe, which is situated in the tropical, climatic zone and covering an area of $390,757 \mathrm{~km}^{2}$. Two general bio-climatic zones are discernible with one covering most of central Zimbabwe with a north-eastern stretch (the Highveld) and the other comprising large parts of the South and the West (the Lowveld). The climatic year is divided into four seasons: rainy (December-February), post-rainy (March-May), cold-dry (June-August) and dry (September-November) (Shiff et al., 1979; Chandiwana et al., 1987; Mukaratirwa and Kristensen, 1995; Unganai, 1996).

\section{Approach}

A dataset from 1988 (Makura and Kristensen, 1991) was used and a collection survey in 2012 (data presented here) was designed not only to match the earlier dataset in terms of collection method, but also to fulfil the requirements of the Maxent method (Phillips et al., 2006) that was used to model the distribution of the snail species. Collection took place in May and June for the 1988 survey, and in June and the beginning of July for the 2012 survey; i.e. both were carried out after the rain season.

\section{Sampling method}

The 1988 survey covered most of Zimbabwe, whereas the 2012 survey was limited to a smaller area (Fig. 1). Since a global positioning system (GPS) technology was not available at the time of the earlier survey, the geographical coordinates were not obtained in the field but assigned to a grid cell in a predefined 26.5 x $26.5 \mathrm{~km}$ national grid. For the purpose of this study, the collection sites were georeferenced with the geometrical centre of the respective grid cell. Choice of sampling site was left ad libitum to the sampling teams. The sampling sites in the 2012 survey, on the other hand, were georeferenced by a GPS instrument (Garmin eTrex H; Garmin Ltd., Southampton, UK), and it was assured that the sites were representative of the full range of Zimbabwe's ecological conditions/habitats. A map of agro-ecological zones, developed by the Food and Agriculture Organization (FAO, 2006) (Fig. 1), was consulted and relevant survey zones identified before following a random-like selection procedure, i.e. using 10-20 km travel distance between sample sites and progressing from primary to secondary to tertiary roads and sometimes continuing on foot in the field to reach particularly remote

Table 1. Role of snail and hosts in some trematode-induced diseases.

\begin{tabular}{llllll}
\hline $\begin{array}{l}\text { Intermediate } \\
\text { host }\end{array}$ & Parasite & $\begin{array}{l}\text { Definitive } \\
\text { host }\end{array}$ & $\begin{array}{l}\text { Disease in the } \\
\text { definitive host }\end{array}$ & $\begin{array}{l}\text { Prevalence in } \\
\text { Zimbabwe }\end{array}$ & $\begin{array}{l}\text { Adverse effects in the definitive } \\
\text { host }\end{array}$ \\
\hline $\begin{array}{l}\text { Bulinus } \\
\text { globosus }\end{array}$ & $\begin{array}{l}\text { Schistosoma } \\
\text { haematobium }\end{array}$ & Man & $\begin{array}{l}\text { Urogenital } \\
\text { schistosomiasis }\end{array}$ & $\begin{array}{l}18.0 \% \\
\text { (Midzi et al., 2011) }\end{array}$ & $\begin{array}{l}\text { Cognitive disability, } \\
\text { malnutrition, organ damage }\end{array}$ \\
$\begin{array}{l}\text { Biomphalaria } \\
\text { pfeifferi }\end{array}$ & $\begin{array}{l}\text { Schistosoma } \\
\text { mansoni }\end{array}$ & Man & $\begin{array}{l}\text { Intestinal } \\
\text { schistosomiasis }\end{array}$ & $\begin{array}{l}7.2 \% \\
\text { (Midzi et al., 2011) }\end{array}$ & $\begin{array}{l}\text { Cognitive disability, } \\
\text { malnutrition, organ damage }\end{array}$ \\
$\begin{array}{l}\text { Lymnaea } \\
\text { natalensis }\end{array}$ & $\begin{array}{l}\text { Fasciola } \\
\text { gigantica }\end{array}$ & Man & Fascioliasis & $\begin{array}{l}0.04-5.0 \% \\
\text { (Goldsmid, 1968; }\end{array}$ & Organ damage, malnutrition \\
& Gammond, 1974) & <azing animals \\
& Fascioliasis & $\begin{array}{l}<9 \% \\
\text { (Pfukenyi et al., 2005) }\end{array}$ & $\begin{array}{l}\text { Poor meat- and milk yield, } \\
\text { death }\end{array}$ \\
\hline
\end{tabular}




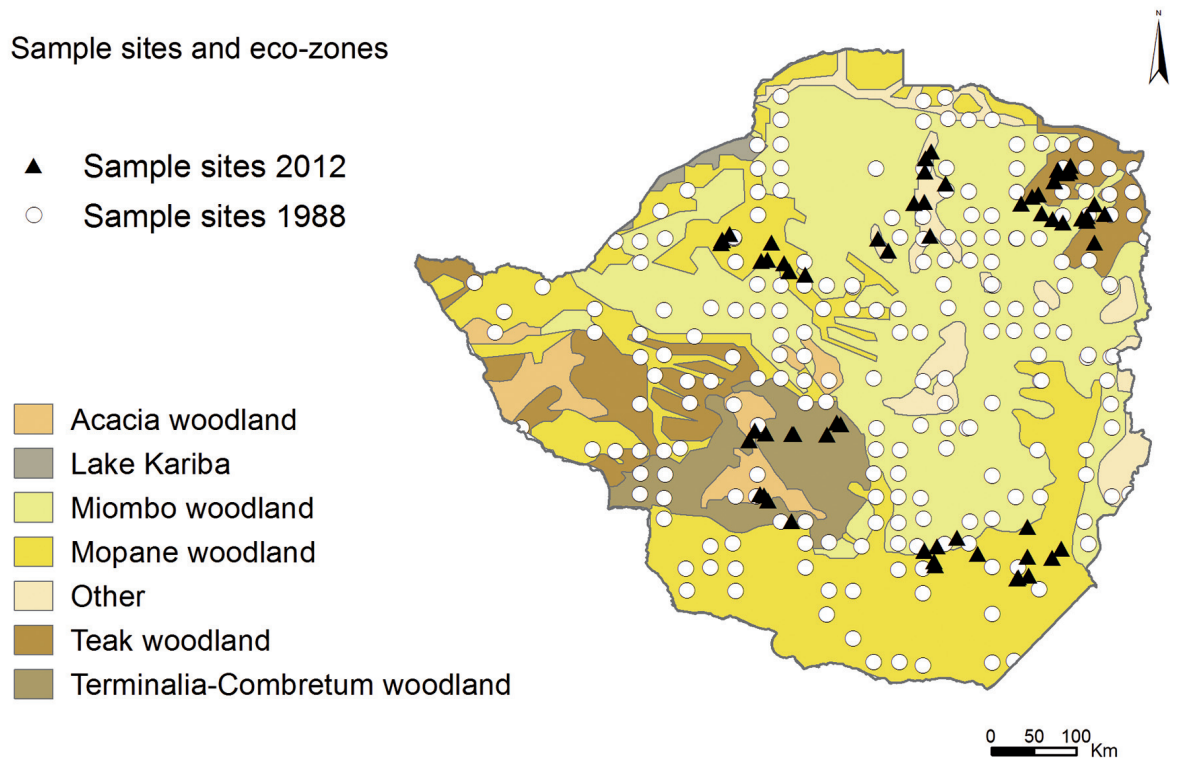

Fig. 1. Sampling locations. Locations overlaid map of ecological zones (FAO, 2006).

sampling sites. Following this design, quite a few less accessible areas were entered, thus avoiding bias towards sampling only along major roads that could potentially correlate with the variables under investigation.

Snail collection methods and equipment used in the two snail collection missions followed Coulibaly and Madsen (1990) and snail identification that of Brown and Kristensen (1989). Skilled regional sampling teams were employed in 1988 whereas four researchers carried out the sampling in 2012. Potential habitats were scooped with a $20 \times 20 \mathrm{~cm}$ sieve mounted on a $2 \mathrm{~m}$ stick and snails were occasionally picked from the substratum or submerged vegetation. Water temperature, $\mathrm{pH}$ and electro conductivity were measu- red by DIST ${ }^{\circledR 5}$, (Hanna Instruments Inc.; Ann-Arbor, USA) and water velocity with a Marsh-McBirney flow-meter, model 201D (Marsh-McBirney Inc.; Frederick, USA) of the probe-type.

\section{Environmental layers}

Sources and specifics of environmental data are listed in Table 2. The temperature $\left(\mathrm{T}_{\max }\right.$ and $\left.\mathrm{T}_{\min }\right)$, number of wet days (Wetdays), potential evapotranspiration (PET) were obtained from the Climate Research Unit (CRU) dataset (Harris et al., 2013) and downscaled to a $10 \mathrm{~km}$ resolution by a Bayesian kriging interpolation method (Empirical Bayesian Kriging Toolbox in ArcMap v. 10.1; ESRI, Redlands, USA).

Table 2. Specifics of the environmental data used for habitat suitability modelling.

\begin{tabular}{|c|c|c|c|c|}
\hline \multirow{2}{*}{ Variable } & \multicolumn{2}{|c|}{ Data source } & \multirow{2}{*}{ Resolution (km) } & \multirow{2}{*}{ Reference } \\
\hline & 1988 & 2012 & & \\
\hline $\mathrm{T}_{\max }$ & $\mathrm{CRU}^{\mathrm{a}}$ & $\mathrm{CRU}^{\mathrm{a}}$ & \multirow{8}{*}{$\begin{array}{r}10 * \\
10 * \\
10 \\
10 * \\
10 * \\
8 \\
10 \\
0.09\end{array}$} & \multirow{8}{*}{$\begin{array}{l}\text { www.badc.nerc.ac.uk } \\
\text { www.badc.nerc.ac.uk } \\
\text { ftp.cpc.ncep.noaa.gov/fews } \\
\text { www.badc.nerc.ac.uk } \\
\text { www.badc.nerc.ac.uk } \\
\text { www.nasa.gov/centers/goddard } \\
\text { www.isric.org } \\
\text { www.cgiar-csi.org/data }\end{array}$} \\
\hline $\mathrm{T}_{\min }$ & $\mathrm{CRU}^{\mathrm{a}}$ & $\mathrm{CRU}^{\mathrm{a}}$ & & \\
\hline Rainfall & $\mathrm{ARC}^{\mathrm{b}}$ & $\mathrm{ARC} 2^{\mathrm{b}}$ & & \\
\hline Wetdays & $\mathrm{CRU}^{\mathrm{a}}$ & $\mathrm{CRU}^{\mathrm{a}}$ & & \\
\hline $\mathrm{PET}^{\mathrm{c}}$ & $\mathrm{CRU}^{\mathrm{a}}$ & $\mathrm{CRU}^{\mathrm{a}}$ & & \\
\hline $\mathrm{NDVI}^{\mathrm{d}}$ & $\mathrm{AVHRR}^{\mathrm{c}}$ & AVHRR $^{c}$ & & \\
\hline Soil pH & ISRIC-WISE ${ }^{f}$ & ISRIC-WISE $^{f}$ & & \\
\hline Elevation & SRTM DED & & & \\
\hline
\end{tabular}

${ }^{\mathrm{a} C l i m a t e}$ research unit (CRU); ${ }^{\mathrm{b}} \mathrm{African}$ rainfall climatology, version 2.9; ${ }^{\mathrm{c} p o t e n t i a l}$ evapotranspiration; ${ }^{\mathrm{d}}$ normalized difference vege-

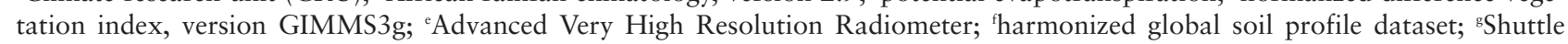
Radar Topography Mission - Digital Elevation Database version 4.1; *interpolated from 50 km. 

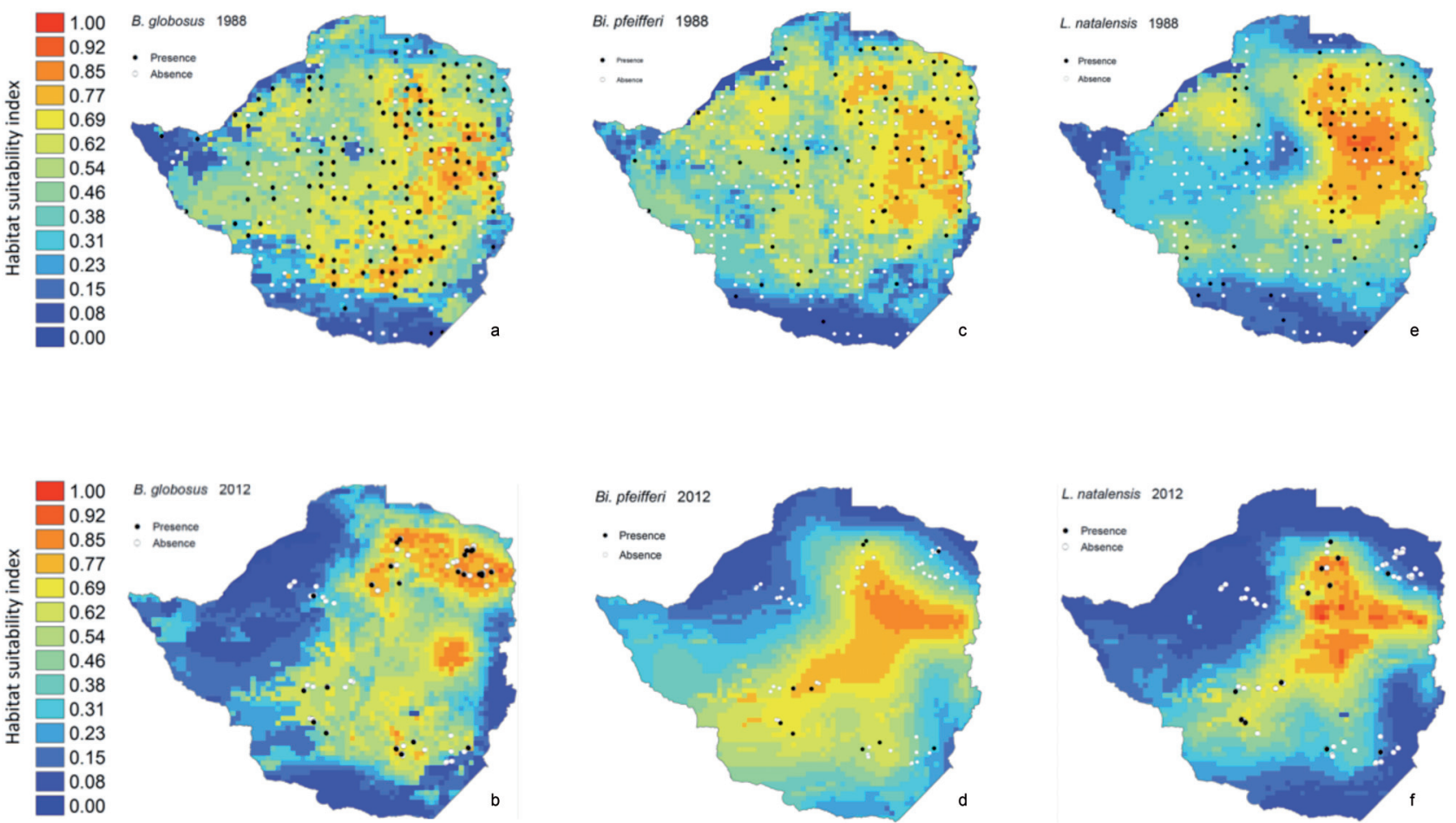

Fig. 2. Modelled predictions of habitat suitability of Bulinus globosus (a and b), Biomphalaria pfeifferi (c and d), and Lymnaea natalensis (e and f). Warmer colours indicate increasing habitat suitability.

The normalized difference vegetation index (NDVI), version GIMMS3g (Pinzon, in press) was provided directly by the data holders. We also used African Rainfall Climatology version 2.9 (ARC2) (Novella and Thiaw, 2012), a modelled dataset based on satellite measurements and rain gauge data from meteorological stations.

A three month average (March-May) was used for $\mathrm{T}_{\max }, \mathrm{T}_{\min }, \mathrm{ARC} 2, \mathrm{NDVI}$, Wetdays, PET and NDVI because this is the period in Zimbabwe when these variables are believed to have the highest impact on snail population development. The $\mathrm{pH}$ data were obtained from the ISRIC-WISE harmonized global soil profile dataset (http://www.isric.org), where measurements of $\mathrm{pH}$ in soil water have been modelled and expressed as a smooth surface. Altitude data from the Shuttle Radar Topography Mission (SRTM) Digital Elevation Database version 4.1 (http://www2.jpl.nasa.gov/srtm) were resampled from a $90 \mathrm{~m}$ resolution to a $500 \mathrm{~m}$ one.

\section{Model implementation}

Two models, one for each time period, was developed for each species resulting in three model-pairs that were compared in order to extract information regarding temporal changes. Environmental data matching in time, was applied for each model except for variables static in time, e.g. soil $\mathrm{pH}$ and altitude. Model performance was expressed as the area under (the receiver operator characteristic) curve (AUC) supported by sensitivity and specificity (Table 3). A Jack-knife procedure, implemented in Maxent, was used to quantify the explanatory power of each environmental variable (Table 3).

\section{Results}

In 2012, a total of 64 locations were sampled and 1,390 snail specimens collected, with 26 locations found to harbour B. globosus, 11 Bi.pfeifferi, and 12 L. natalensis. In 1988, 364 locations were sampled, 121 locations were found to harbour B. globosus, 64 Bi. pfeiffe$r i$ and 74 L. natalensis (Fig. 1). Collection localities were rivers and streams, lakes, canals and dams.

Figs. 2a and 2b shows the Maxent predictions of habitat suitability for B. globosus. The model predicted that the Highveld, especially the north-eastern part, should contain locations with relatively high probabilities of finding suitable living-conditions for snails, while large areas to the South were predicted to be non-suitable habitats. The prediction for 2012 (Fig. 2b) illustrates that fewer locations were likely to be 

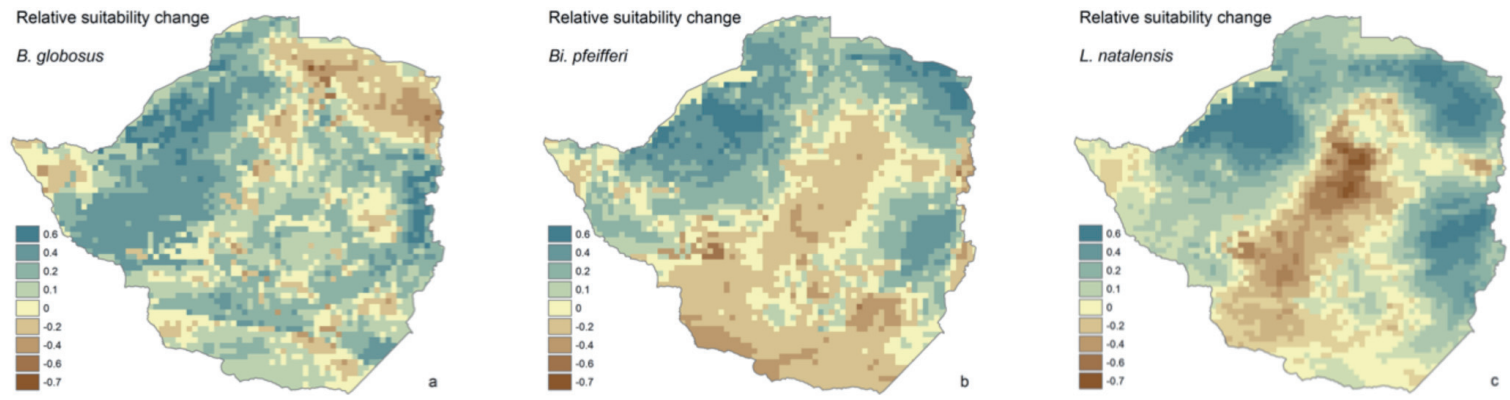

Fig. 3. Changes of predicted suitable habitats for Bulinus globosus (a) Biomphalaria pfeifferi (b) and Lymnaea natalensis (c). Brown colours indicate increased habitat suitability and blue decreased suitability.

suitable compared to 1988 (Fig. 2a) and that relatively large areas of unsuitable habitat for B. globosus were apparent in 2012 (Fig. 2b). The highest magnitude of change towards higher habitat suitability had occurred in the Northwest (Fig. 3a).

The predicted distribution of Bi.pfeifferi habitats is depicted in Figs. 2c and 2d. The central Highveld constituted the most suitable habitat. In 2012, larger areas were predicted to be highly unsuitable compared to 1988 , but a shift was detected in parts of central Zimbabwe with areas that were not previously suitable, now having turned into more suitable habitats. This trend was found to be especially pronounced in the South (Fig. 3b).

The area predicted to have suitable habitats for L. natalensis (Figs. 2e and 2f) according to the model had declined significantly between 1988 and 2012; only the very central Highveld was now predicted to be suitable and large parts of the whole country appeared unsuitable. For the 1988 survey, the model indication was that most of Zimbabwe were then suitable for L. natalensis, with only limited zones of unsuitable habitats here and there. It was mainly areas with previous intermediate habitat suitability that had changed to become highly unsuitable in 2012, even though the changes in terms of suitability values were not large (Fig. 3c).

The AUC values ranged from 0.837 to 0.951 indicating good model performance with sensitivity levels between $72 \%$ and $94 \%$. Specificity was, however, rather low at $33 \%$ to $72 \%$ (Table 3 ).

\section{Discussion}

The aim of this work was to map, model and predict the potential distribution of suitable habitats for three intermediate host snail species with regard to two widely, spaced periods of time and to explore if any

Table 3. Test statistics for six models from three snail species in two time periods.

\begin{tabular}{|c|c|c|c|c|c|c|}
\hline & \multicolumn{2}{|c|}{ Bulinus globosus } & \multicolumn{2}{|c|}{ Biomphalaria pfeifferi } & \multicolumn{2}{|c|}{ Lymnaea natalensis } \\
\hline & 2012 & 1988 & 2012 & 1988 & 2012 & 1988 \\
\hline $\mathrm{AUC}^{\mathrm{a}}$ & 0.951 & 0.893 & 0.837 & 0.891 & 0.916 & 0.875 \\
\hline Sensitivity & 58 & 72 & 33 & 37 & 44 & 46 \\
\hline Specificity & 91 & 72 & 94 & 88 & 91 & 83 \\
\hline Contribution & $\%$ & $\%$ & $\%$ & $\%$ & $\%$ & $\%$ \\
\hline $\mathrm{T}_{\max }$ & 35.2 & 23.1 & 0 & 3.9 & 0 & 3.9 \\
\hline $\mathrm{T}_{\min }$ & 2.4 & 4.8 & 95.3 & 1.0 & 84.8 & 1.0 \\
\hline Rainfall & 3.2 & 13 & 0 & 9.7 & 12.4 & 9.7 \\
\hline $\mathrm{NDVI}^{\mathrm{b}}$ & 0.9 & 7.0 & 0 & 19.5 & 0 & 9.7 \\
\hline Wetdays & 44.5 & 33.5 & 0 & 35.6 & 0.8 & 35.6 \\
\hline PET $^{\mathrm{c}}$ & 3.1 & 4.6 & 0 & 14.4 & 0 & 14.4 \\
\hline Elevation & 3.1 & 3.4 & 0 & 9.7 & 0 & 9.7 \\
\hline $\mathrm{pH}$ & 7.6 & 10.6 & 4.7 & 6.1 & 2.0 & 6.1 \\
\hline
\end{tabular}

${ }^{\mathrm{a}}$ Area under (the receiver operator characteristic) curve; ${ }^{\mathrm{b}}$ normalized difference vegetation index, version GIMMS3g; ${ }^{\mathrm{p}}$ otential evapotranspiration. 
correlation with climate change could be detected. Modelling was carried out with Maxent software (Phillips et al., 2006) using data on snail presence and environmental predictors known to influence snail macroecology. In terms of species biology and ecology, this method is attractive and also more intuitive compared to classic mathematical parameterisation of species responses to its environment based on controlled laboratory experiments or semi-natural setups.

The modelling results depicted in Fig. 2, describes graduated habitat suitability across Zimbabwe. The three species have different foci but overlap at most locations. Changes in spatial distribution over time were apparent with a trend towards more unsuitable habitats, but pockets of suitable habitats were also found in areas that were previously unsuitable. Interestingly, by comparing the left column of maps in Figs. 2a, 2c and 2e, which represent the 1988 survey to the right column in Figs. $2 \mathrm{~b}, 2 \mathrm{~d}$ and $2 \mathrm{f}$, which represents the 2012 survey, it is immediately obvious that suitable snail habitats (warmer colours) have generally been reduced for all three snail species with the main reduction occurring in areas that also had low suitability values in 1988. Nevertheless, patches within Zimbabwe, predicted as non-suitable in the earlier survey were now predicted to be suitable (Fig. 3). However, even though snail habitat suitability decrease at the country level, which should lead to less disease in the definite host, this change cannot be expected to be uniform. Indeed, prevalence might even increase at certain locations, so health units might actually need to augument the intervention capacity.

For comparative studies, one must be certain to use datasets of identical quality in order to be able to deduce changes not caused by differences in the systems being compared. First, the actual sampling at the sample sites should be identical in terms of technique and intensity. During sampling in 2012, two people sampled for 30 min whereas two people sampled for $45 \mathrm{~min}$ in 1988. In both years, the personnel had extensive experience in sampling fresh-water snails. Second, the selection of study sites should not be biased. In 2012, the sites were identified by the randomlike procedure described above, whereas in 1988 sampling teams were directed to choose collection sites ad libitum. Third, geographical precision of collection sites should match that of the environmental layers. The coordinates of survey locations in 2012 had a precision of a few meters, whereas georeferencing by GPS was not an option in 1988. In 1988, the field teams were instructed to sample in the above mentioned 26.5 x $26.5 \mathrm{~km}$ grid cells and the observations were assi- gned to the centre points of the cells. There are up to nine different environment values in one of these grid cells and this could clearly generate an error when overlaying environmental layers. However, the magnitude of this error becomes somewhat reduced when the high number of observations in 1988 is considered since this increases the likelihood of neighbouring environmental grid cells having similar values. The potential error is futher muted by the fact that some of the environmental predictors are daily or 10-day averages of values from a period of 3 months. Imprecision of the georeferencing in 1988 is not considered to conflict with the overall interpretations of the results. Fourth, sampling success can vary between seasons due to changes of the habitat (volume of water) and also snail population dynamics (abundance and body size). Sampling was carried out after the rainy season, which increased the chance of finding the snails in their preferred habitats since water bodies are reduced in volume, so population densities are at its highest and many specimens have grown to full size.

Since a nationwide snail collection survey was not an option in 2012, care was taken to assure that the limited number of samples was qualitatively comparable to those of 1988. Obtaining snail samples from eco-regions similar to that of the entire environmental space of the modelling domain applied more weight to Maxent's AUC performance measure.

The AUC seen in Table 3 is the measure of model performance supported by measures of sensibility and specificity (Liu, 2005). Calculation of specificity and sensitivity was enabled after partitioning the observation into true positives, true negatives, false positives and false negatives by using the "Maximum training sensitivity plus specificity statistics" output from Maxent as a threshold criterion following the recommendation of $\mathrm{Hu}$ and Jiang (2011). The high values delivered $(>0.8)$ is a strong indication that the models applied are indeed good at predicting suitable habitats but low sensitivity indicates that potential absence of presence is not well predicted. However, they are not good at predicting where the snails are just potentially present.

Extensive research in snail ecology and results from numerous modelling studies, describe which candidate variables to use (Kristensen et al., 2001; Malone et al., 2001; Stensgaard et al., 2006, 2013; Zhou et al., 2008; Stensgaard, 2011). For the purpose of comparing two different time periods, attention was paid to identifying and compiling environmental datasets with a quality that justifies temporal comparison. In order to isolate climate variability as the only source to any observed change, consideration was given to data 
sources, collection method and the computing approach. Other factors that are known to affect snail distribution, such as land use and snail control were not included as no such period-specific data could be identified. Comparatively few environmental variables were explored in comparison to other studies (Moffett et al., 2007; Stensgaard, 2011; Valencia-Lopez et al., 2012; Stensgaard et al., 2013) because few environmental variables were available for the earlier period at the desired resolution. Only variables shown to have been of importance in earlier research were included, though a dataset of the mean daily temperature from the CRU dataset (Harris et al., 2013) was left out due to its high correlation to other datasets. Temperature, rainfall and humidity contributed most to the models, whereas soil $\mathrm{pH}$ and altitude contributed to a lesser degree.

The temperature data were interpolated after having been downloaded and this might be of concern. However, when comparing the interpolated temperature data to long-term data from the WorldClim dataset (Hijmans et al., 2005) by simply subtracting values, pixel by pixel, a monotonic landscape appeared. This indicates that the interpolation maintained the climate patterns of Zimbabwe from year to year although at a diffrent temperature.

Importantly, when considering relevant candidate environmental variables to be used in a model, the ecology of the species in question needs to be taken into consideration. The response of survival and reproduction rate to temperature has been described in a number of studies (Appleton, 1978; Pflüger, 1981; Woolhouse and Chandiwana, 1990a, 1990b; MasComa et al., 2005; Zhou et al., 2008) and temperature is therefore an obvious candidate. The analysis of model variable contribution in this study showed temperature to be the variable with the highest explanatory power in four models out of six (Table 3).

Different expressions of temperature used in this study contribute differently to the models. This might be an artefact but could also be due to specific snail biology. For example, studies have shown that the minimum temperature can be a limiting factor as shown with reference to the "freezing line" proposed by Zhou et al. (2008). Elevated night-time minimum temperatures, such as experienced in Zimbabwe early in the 1988-2012 period, and also possibly later (Unganai, 1996), may open up new areas of suitable habitats in regions where low temperature is the current limiting factor. On the other hand, higher maximum temperature may cause habitats to disappear. The fact that temperature played an important role in our models, indicate that climate change may significantly alter the future spatial distribution of all three snail species studied. It should be mentioned that the temperature dataset was ambient temperature, and that it is only a proxy for water temperature. The relationship between changes in ambient temperature versus changes in water temperature may not be linear (McCreesh and Booth, 2013), i.e. snails may experience a more pronounced or a reduced change than what the temperature data suggest.

Precipitation and humidity only indirectly affect snails as these two predictors merely describe the probability of an aquatic environment being present, while $\mathrm{pH}$ appears to play a role in the snail's ecological space as it has been shown to contribute to the models (Table 3) even though the biological interaction is not intuitive (Malek, 1958; Appleton, 1978; Appleton and Madsen, 2012; Lange et al., 2013).

\section{Conclusion}

Models based on snail presence and climatic/environmental input for two different time periods suggest that snail populations are experiencing less favourable conditions in some parts of Zimbabwe in 2012 compared to those of 1988 . Indeed, some populations are already at the edge of their area of occupation, and might free parts of Zimbabwe from schistosomiasis and fascioliasis altogether. It is also predicted that snails will find suitable habitats in some areas not predicted suitable in 1988 possibly leading to an increased risk of infections in some new areas.

The predicted changes of suitable snail habitat distribution in Zimbabwe parallel that of the observed change in climate variables. The change towards a drier and warmer climate found mimics that of the contemporary climate change models developed under the International Panel of Climate Change (IPCC, 2007). Our results support climate change impact assessments of future intermediate host snail distribution. Applying detailed down-scaled climate models can provide further information in this field.

\section{Acknowledgements}

National Institute of Health Research, Ministry of Health and Child Welfare, Harare, Zimbabwe is acknowledged for administrative and logistic support, Frank Kristoffersen for help with for data conversion, and Rasmus Fensholt at the Department of Geosciences and Natural Resource Management, University of Copenhagen, Denmark for providing and formatting NDVI, version GIMMS3-g data. 


\section{References}

Appleton C, Madsen H, 2012. Human schistosomiasis in wetlands in southern Africa. Wetl Ecol Manag 20, 253-269.

Appleton CC, 1978. Review of literature on abiotic factors influencing the distribution and life cycles of bilharziasis intermediate host snails. Malacol Rev 11, 1-25.

Brown DS, Kristensen TK, 1989. A field guide to African freshwater snail, southern African species. Charlottenlund: Danish Bilharziasis Laboratory.

Chandiwana SK, Taylor P, Makura O, 1987. Prevalence and distribution of Schistosoma mattheei in Zimbabwe. Ann Soc Belg Med Trop 67, 167-172.

Chimbari MJP, Makoni P, Madsen H, 2007. Impact of Sargochromis codringtonii (Teleostei: Cichlidae) on pulmonate snails in irrigation ponds in Zimbabwe. Afr J Aquat Sci 32, 197-200.

Coulibaly G, Madsen H, 1990. Seasonal density fluctuations of intermediate hosts of schistosomes in two streams in Bamako, Mali. J Afr Zool 104, 201-212.

FAO, 2006. Fertilizer use by crop in Zimbabwe. Rome: Food and Agriculture Organization.

Fürst T, Keiser J, Utzinger J, 2012. Global burden of human food-borne trematodiasis: a systematic review and metaanalysis. Lancet Infect Dis 12, 210-221.

Goldsmid JM, 1968. Studies on intestinal helminths in African patients at Harari Central Hospital, Rhodesia. Trans R Soc Trop Med Hyg 62, 619-629.

Hammond JA, 1974. Human infection with the liver fluke Fasciola gigantica. Trans R Soc Trop Med Hyg 68, 253-254.

Harris I, Jones PD, Osborn TJ, Lister DH, 2013. Updated highresolution grids of monthly climatic observations - the CRU TS3.10 Dataset. Int J Climatol 34, 626-642.

Hijmans RJSE, Cameron JL, Parra P, Jones G, Jarvis A, 2005. Very high resolution interpolated climate surfaces for global land areas. Int J Climatol 25, 1965-1978.

Hopkins DR, 1992. Homing in on helminths. Am J Trop Med Hyg 46, 626-634.

Hu J, Jiang Z, 2011. Climate change hastens the conservation urgency of an endangered ungulate. PLoS One 6, e22873.

IPCC, 2007. Climate change 2007: the physical science basis. Cambridge, Cambridge University Press, 996 pp.

Keiser J, Utzinger J, 2005. Emerging foodborne trematodiasis. Emerg Infect Dis 11, 1507-1514.

Kristensen TK, Malone JB, McCarroll JC, 2001. Use of satellite remote sensing and geographic information systems to model the distribution and abundance of snail intermediate hosts in Africa: a preliminary model for Biomphalaria pfeifferi in Ethiopia. Acta Trop 79, 73-78.

Lange CN, Kristensen TK, Madsen H, 2013. Gastropod diversity, distribution and abundance in habitats with and without anthropogenic disturbances in Lake Victoria, Kenya. Afr J
Aquat Sci 38, 295-304.

Liu C, Berry PM, Dawson TP, Pearson RG, 2005. Selecting thresholds of occurrence in the prediction of species distributions. Ecography 28, 385-393.

Makura O, Kristensen TK, 1991. National freshwater snail survey of Zimbabwe. The $10^{\text {th }}$ International Malocological Congress. Tübingen, Germany, p. 227-232.

Malek EA, 1958. Factors conditionning the habitat of bilharziasis intermediate hosts of the family of Planorbidae. Bull World Health Organ 18, 785-818.

Malone JB, Yilma JM, McCarroll JC, Erko B, Mukaratirwa S, Zhou X, 2001. Satellite climatology and the environmental risk of Schistosoma mansoni in Ethiopia and east Africa. Acta Trop 79, 59-72.

Mas-Coma S, 2004. Human fascioliasis: epidemiological patterns in human endemic areas of South America, Africa and Asia. Southeast Asian J Trop Med Public Health 35, 1-11.

Mas-Coma S, Bargues MD, Valero MA, 2005. Fascioliasis and other plant-borne trematode zoonoses. Int J Parasitol 35, $1255-1278$.

McCreesh N, Booth M, 2013. Challenges in predicting the effects of climate change on Schistosoma mansoni and Schistosoma haematobium transmission potential. Trends Parasitol 29, 548-555.

Midzi N, Mduluza T, Chimbari JM, Mutapi F, Tshuma C, Charimari L, Mhlanga G, Manangazira P, Phiri I, Munyati SS et al., 2011. Report on the National schistosomiasis and soil transmitted helminths survey in Zimbabwe. Ministry of Health and Child Welfare, Zimbabwe.

Moffett A, Shackelford N, Sarkar S, 2007. Malaria in Africa: vector species' niche models and relative risk maps. PLoS One 2, e824.

Mukaratirwa S, Kristensen TK, 1995. A review on status of vector snails of urinary schistosomiasis in Zimbabwe. In: A status of research on medical malariology in relation to schistosomiasis in Africa. Harare, Zimbabwe, p. 197-204.

Mukaratirwa S, Sieglsmund HR, Kristensen TK, Chandiwana SK, 1996. Population genetics and genetic variability of Bulinus globosus (Gastropoda: Planorbidae) from the two main river systems in Zimbabwe. J Hered 87, 288-294.

Novella NS, Thiaw WM, 2012. African rainfall climatology version 2 for famine early warning systems. J Appl Meteorol Clim 52, 588-606.

Pflüger W, 1981. Experimental epidemiology of schistosomiasis. Z Parasitenkd 66, 221-229.

Pfukenyi DM, Monrad J, Mukaratirwa S, 2005. Epidemiology and control of trematode infections in cattle in Zimbabwe: a review. J S Afr Vet Assoc 76, 9-17.

Pfukenyi DM, Mukaratirwa S, Willingham AL, Monrad J. 2006. Epidemiological studies of Fasciola gigantica infections in cattle in the Highveld and Lowveld communal grazing areas of Zimbabwe. Onderstepoort J Vet Res 73, 37-51. 
Phillips SJ, Anderson RP, Schapire RE. 2006. Maximum entropy modeling of species geographic distributions. Ecol Model 190, 231-259.

Pinzon JE, in press. A non-stationary 1981-2012 AVHRR NDVI3g time series. Accepted for Remote Sensing, Special issue "Monitoring Global Vegetation with AVHRR NDVI3g Data (1981-2011)”. In press.

Rim HJ, Farag HF, Sornmani S, Cross JH. 1994. Food-borne trematodes: ignored or emerging? Parasitol Today 10, 207-209.

Shiff CJ, Coutts WCC, Yiannakis C, Holmes RW, 1979. Seasonal patterns in the transmission of Schistosoma haematobium in Rhodesia, and its control by winter application of molluscicide. Trans R Soc Trop Med Hyg 73, 375-380.

Steinmann P, Keiser J, Bos R, Tanner M, Utzinger J, 2006. Schistosomiasis and water resources development: systematic review, meta-analysis, and estimates of people at risk. Lancet Infect Dis 6, 411-425.

Stensgaard AS, 2011. Patterns and determinants of three snailborne parasitic infections in Zimbabwe: relative roles of climatic data sources, environment and biotic interactions. $\mathrm{PhD}$ thesis, University of Copenhagen.

Stensgaard AS, Jørgensen A, Kabaterina NB, Rahbek C, Kristensen TK, 2006. Modelling freshwater snail habitat sui- tability and areas of potential snail-borne diesase transmission in Uganda. Geospat Health 1, 93-104.

Stensgaard AS, Utzinger J, Vounatsou P, Hürlimann E, Schur N, Saarnak CFL, Simoonga C, Mubita P, Kabatereine NB, Tchuem Tchuenté LA et al., 2013. Large-scale determinants of intestinal schistosomiasis and intermediate host snail distribution across Africa: does climate matter? Acta Tropica 128, 378-390.

Unganai LS, 1996. Historic and future climatic change in Zimbabwe. Clim Res 6, 137-145.

Valencia-Lopez N, Malone JB, Carmona CG, Velasquez LE, 2012. Climate-based risk models for Fasciola hepatica in Colombia. Geospat Health 6, 67-85.

Woolhouse MEJ, Chandiwana SK, 1990a. Population biology of the freshwater snail Bulinus globosus in the Zimbabwe Highveld. J Appl Ecol 27, 41-59.

Woolhouse MEJ, Chandiwana SK. 1990b. Population dynamics model for Bulinus globosus, intermediate host for Schistosoma haematobium, in river habitats. Acta Trop 47, 151-160.

Zhou XN, Yang GJ, Yang K, Wang XH, Hong QB, Sun LP, Malone JB, Kristensen TK, Bergquist NR, Utzinger J, 2008. Potential impact of climate change on schistosomiasis transmission in China. Am J Trop Med Hyg 78, 188-194. 